\title{
Structure-Function Relationships of ErbB RTKs in the Plasma Membrane of Living Cells
}

\author{
Donna J. Arndt-Jovin, Michelle G. Botelho, and Thomas M. Jovin \\ Laboratory of Cellular Dynamics, Max Planck Institute for Biophysical Chemistry, 37077 Göttingen, Germany \\ Correspondence: djovin@gwdg.de
}

We review the states of the ErbB family of receptor tyrosine kinases (RTKs), primarily the EGF receptor (EGFR, ErbB1, HER1) and the orphan receptor ErbB2 as they exist in living mammalian cells, focusing on four main aspects: (1) aggregation state and distribution in the plasma membrane; (2) conformational features of the receptors situated in the plasma membrane, compared to the crystallographic structures of the isolated extracellular domains; (3) coupling of receptor disposition on filopodia with the transduction of signaling ligand gradients; and (4) ligand-independent receptor activation by application of a magnetic field.

$T^{\mathrm{h}}$ his review deals exclusively with the disposition and function of the human ErbB (HER) family of receptor tyrosine kinases (RTKs) in the plasma membrane of living cells. We have divided the material into four main topics: (1) distribution and aggregation state of ErbB family members; (2) the 3D structure of the ErbB1 and ErbB2 receptors; (3) the role of receptors located on extensions (filopodia) of the cell body; and (4) the phenomenon and implications of nonligand-dependent activation of the receptors.

\section{DISTRIBUTION OF ErbB FAMILY MEMBERS IN THE PLASMA MEMBRANE OF LIVING CELLS}

The association state(s) and activities of the ErbB family members in intact living cells differ widely depending on the expression level (num- ber per cell) and the distribution (density, state of homo- and heteroassociation) of each receptor. There are numerous, highly contradictory views about the aggregation state of the receptors in the literature. During the last few years more accurate assessments of receptor distribution have been conducted on living rather than fixed cells. In the latter case, numerous artifacts account for important quantitative discrepancies. One example is the failure of formaldehyde fixation to prevent receptor redistribution (Brock et al. 1999; Tanaka et al. 2010). A more fundamental consideration relates to the hierarchical organization of the plasma membrane, extensively investigated and most recently reviewed by Kusumi et al. (2011). These investigators propose the existence of (1) a mesoscale (40-300 nm) compartmentalization with actin cytoskeletal "fences" and transmembrane protein "pickets," (2) lipid raft domains (2-

Editors: Joseph Schlessinger and Mark A. Lemmon

Additional Perspectives on Signaling by Receptor Tyrosine Kinases available at www.cshperspectives.org

Copyright (C) 2014 Cold Spring Harbor Laboratory Press; all rights reserved; doi: 10.1101/cshperspect.a008961

Cite this article as Cold Spring Harb Perspect Biol 2014;6:a008961 
D.J. Arndt-Jovin et al.

$20 \mathrm{~nm}$ ), and (3) oligomeric complexes of membrane-associated proteins $(3-10 \mathrm{~nm})$. Signal transduction is mediated by cooperative interactions (varying in strength) of and in these domains. Such interactions involve thermal fluctuations, and molecular redistribution and conformational transitions induced by binding and enzymatic action. Temperature clearly plays a critical role in all of these phenomena. Eukaryotic cells exist primarily between $18^{\circ} \mathrm{C}$ and $37^{\circ} \mathrm{C}$ in their respective organisms, undergoing cell death outside this range. The membrane composition and domain structure are intimately connected to these optimum temperatures. From the biophysical perspective, the challenge is to assess the spatial-temporal organization of activation and deactivation processes and their functional consequences.

There exists a persistent controversy about the existence, nature, and extent of preformed, unliganded dimers and higher-order associated states of the EGF receptor (EGFR, ErbB1, HER1). Much of the published data was acquired using labeled ligands as probes (Gadella and Jovin 1995; Sako et al. 2000; Moriki et al. 2001; Martin-Fernandez et al. 2002; Tynan et al. 2012) and/or cells expressing high levels of receptor. In the following section we summarize the latest information derived from strictly live cell analyses at room temperature or $37^{\circ} \mathrm{C}$.

Starved cells (HeLa or transfected Chinese hamster ovary [CHO] cells) with 50,000 or fewer ErbB1 receptors and in the absence of serum and autocrine expression of growth factors have no detectable level of activated ErbB1. Two studies using carboxy-terminal, fused green fluorescent protein (GFP) chimeric ErbB1 examined explicitly the levels of receptor monomers, dimers, and oligomers in live cells. Measurements of diffusion by fluorescence correlation spectroscopy (FCS) (Saffarian et al. 2007) and determinations of receptor distribution by number and brightness analysis $(\mathrm{N} \& \mathrm{~B})$ (Nagy et al. 2010), a correlation technique that computes the fluorescence intensities corresponding to single (and thus multiple) receptors (Digman et al. 2008), led to the conclusion that ErbB1 exists almost exclusively as a monomer in such cells and only forms detectable di-
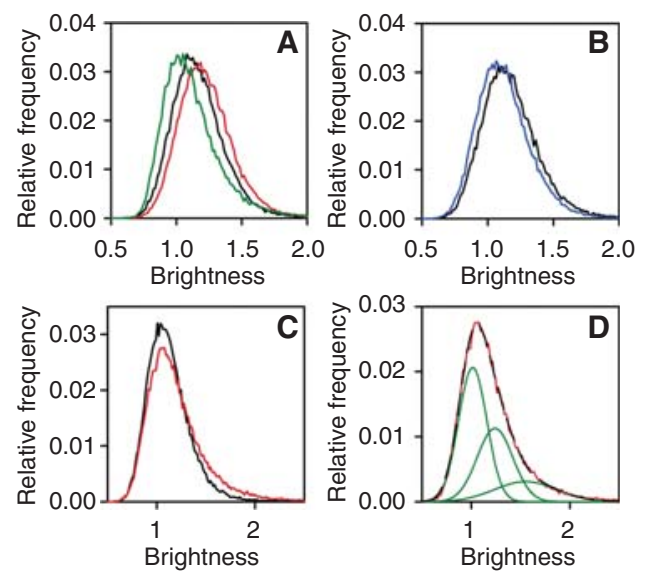

Figure 1. Clustering of ErbB1 in quiescent and EGFstimulated cells measured by N\&B. (A) Starved F1-4 cells expressing $5 \times 10^{5}$ receptors were measured before and after stimulation with EGF for $3 \mathrm{~min}$. The brightness histograms are plotted for quiescent (black line) and the EGF-stimulated cells (red line). The brightness histogram of soluble monomeric eGFP is shown by the green line. (B) Starved F1-4 cells were photobleached until their fluorescence intensity reached $\sim 20 \%$ of the initial value and the brightness histograms of the control (black line) and the bleached (blue line) cells are shown. $(C)$ Brightness histograms of F1-10 cells expressing $5 \times$ $10^{4}$ receptors before ligand (starved [black line]) and after ligand (EGF-stimulated [red line]) addition for 3 min. (D) The brightness histogram of EGF-stimulated F1-10 cells (red line) was fitted by three overlapping Gaussians (green lines). The sum of the three fitted Gaussian distributions perfectly overlapping the experimentally determined histogram is shown by the black, long dashed line. (From Nagy et al. 2010; reproduced, with permission, from the National Academy of Sciences (C) 2010.)

mers and some higher-order aggregates at expression levels of $>10^{5}$ receptors (Fig. 1; Table 1). In the N\&B measurements, addition of EGF caused a rapid dimerization of the receptors, which then associated with clathrin-coated pits and internalized. In the case of cells harboring $5 \times 10^{5}$ receptors there was a concerted shift in the ErbB1 population to a dimer distribution (Fig. 1).

Two independent studies used single-particle tracking (SPT) to assess the coconfinement of ErbB1receptors within the optical resolu- 
Table 1. Molecular brightness values calculated from data as in Figure 1 for ErbB1-eGFP-expressing cells without ligand and after exposure to EGF

\begin{tabular}{lll}
\hline F1-4 cells & & \\
$\begin{array}{l}\text { Molecular brightness } \\
\quad(\mathrm{mol} / \text { cluster })\end{array}$ & Starved cells & $0.158 \pm 0.002(1.3)$ \\
F1-10 cells & Starved cells after photobleaching & $0.128 \pm 0.002(1.0)$ \\
$\begin{array}{l}\text { Molecular brightness } \\
\quad(\mathrm{mol} / \text { cluster })\end{array}$ & Starved cells plus EGF for 3 min & $0.217 \pm 0.003(1.8)$ \\
& Starved cells & $0.122 \pm 0.001(1.0)$ \\
& Starved cells plus EGF for 3 min & $0.175 \pm 0.003(1.5)$
\end{tabular}

Molecular brightness values ( \pm s.E.M.) of quiescent and EGF-stimulated cells are shown in the table. The numbers in parentheses represent the average number of ErbB1-eGFP in a molecular cluster determined by dividing the molecular brightness values of cells with the brightness value of $0.118 \pm 0.002$ for soluble monomeric eGFP fluorescent protein. The displayed values were calculated from 5 to 10 cells. (From Nagy et al. 2010; modified, with permission.)

tion of the microscope (200-300 nm). The diffusion in and out of corrals was determined with Fab fragments (Chung et al. 2010) or nanobodies (Low-Nam et al. 2011) coupled to quantum dots (QDs). Chung et al. found that coconfined receptors had finite "dimer" lifetimes with an increased probability in the lamellipodia. These coconfined receptors did not show the slow diffusion of the activated receptors. However, there was a significant difference in the diffusion of receptors whose "dimers" had a defective dimerization arm in the extracellular domain 2 (revealed by crystallography [Ogiso et al. 2002]). Using two-color QDs Low-Nam et al. calculated off rates for coconfinement and "dimer" formation. These data were consistent with very shortlived unliganded dimers and the absence of correlated diffusion. However, these studies also showed a facilitated coconfinement and more probable dimer association of receptors in cells with high receptor densities such as A431 $(2 \times$ $10^{6}$ ) compared to HeLa cells with a low density $\left(5 \times 10^{4}\right)$. The formation of dimers or higherorder aggregates was not observed without addition of EGF (i.e., a correlated motion of the two receptors was absent). Low-Nam et al. (2011) calculated a decrease in the dimer dissociation rate of only approximately eightfold after EGF binding, but this value may have been an underestimate because tracks were only analyzed for $50 \mathrm{sec}$. Using long-term tracking, we have demonstrated the continued association of activated dimers for $>400 \mathrm{sec}$ (MG Botelho et al., unpubl.) and conclude that SPT confirms the biophysical data gained from the FCS and $\mathrm{N} \& \mathrm{~B}$ analyses. An additional finding of functional significance was the peripheral enrichment in the actin-dependent cortical compartments (Kusumi et al. 2011), offering a means for polarized responses to growth factors (Chung et al. 2010) albeit with a reduced mobility of signaling-competent ErbB1 dimers (Low-Nam et al. 2011).

A number of experiments have been reported utilizing chimeric ErbB1 transgenes with a platelet-derived growth factor (PDGF)-binding domain (Tyson et al. 2003) or extracellular and intracellular domains exchanged with those of other ErbB family members (Wang et al. 1999; Berger et al. 2004). The aim has been to elucidate the mechanism of activation and the importance of the carboxy-terminal tail, the juxtamembrane domain, as well as the transmembrane segment. These issues are more thoroughly treated in other articles in this collection on structural analysis. Suffice it to say that all of the data are compatible with dimerization as a necessary step leading to transphosphorylation. We will deal later in this report with high local densities of ErbB1, achieved by physical means, that may signal without the intervention of a specific ligand.

In contrast to ErbB1, the orphan receptor ErbB2 is found predominantly in aggregates of three to eight molecules as well as in large clusters comprising many hundreds of receptors, as was shown in living cells by $\mathrm{N} \& \mathrm{~B}$ measurements (Nagy et al. 2010), in Förster resonance energy 
D.J. Arndt-Jovin et al.

transfer (FRET) studies using mAbs (Nagy et al. 1998; Szabó et al. 2008), and by high-resolution near-field scanning microscopy (Nagy et al. 1999) and transmission electron microscopy (TEM) (Yang et al. 2007) of fixed samples labeled by immunofluorescence or immunogold, respectively. The dispersion of the large ErbB2 clusters, preferentially associated with rafts, upon addition of cholera toxin (Nagy et al. 2002) or activation by EGF is attributable to preferential formation of ErbB2/ErbB3 heterodimers (Nagy et al. 1999) or ErbB1/ErbB2 heterodimers (Nagy et al. 2010); see Table 2, where data is modified from Nagy et al. (2010). In cells with high receptor density the ErbB2 clusters are by themselves capable of low-level self-activation in the absence of heterodimerization. Another study showed that cells with increased levels of ErbB2 expression exhibited prolonged signaling from ErbB1 from the cellular membrane, presumably because heterodimerization inhibits the normal endocytosis of ErbB1 homodimers through clathrin-coated pits (Offterdinger and Bastiaens 2008). This effect was reversed by addition of an antibody that blocks the dimerization arm of ErbB2.

ErbB3/ErbB2 heterodimers and neuregulin autocrine activation are the hallmarks of ovarian carcinomas and many breast cancers (Gilmour et al. 2002; Holbro et al. 2003). Both cellular proliferation and migration are promoted by this RTK heterodimer through strong upregulation of the PI3-kinase pathway (Smirnova et al. 2011). In fact, the activated ErbB3/ErbB2 heterodimer shows the highest proliferation index (Rubin and Yarden 2001; Citri et al. 2003; Holbro et al. 2003). However, using cross-linking aptamers, Park et al. (2008) showed that ErbB3 is not interspersed in ErbB2 domains but can form inactive homodimers even at levels of 25,000 or fewer receptors/cell, which reside in a different membrane environment than that of activated ErbB2/ErbB3 heterodimers.

Because various cell types express different numbers of the four ErbB family members it has been difficult to determine the comparative signaling strengths of homo- and heterodimer pairs. Zhang et al. (2009) created a clone library of human mammary epithelial cells expressing different levels of ErbB1, ErbB2, and ErbB3 and conducted quantitative analyses of the signal transduction pathway outputs in the presence of EGF or NRG. They reached relevant conclusions about the network structures and the relative activation strength of dimer pairs. The modeling of the network dynamics of the ErbB RTKs is discussed in detail in Volinsky and Kholodenko (2013).

The lipid environment as well as the presence and nature of proteoglycans on the cell membrane influence the distribution of the ErbB family members in different ways and can account for inhibition of activity in given cases as well as resistance to monoclonal antibody tumor therapy. Hakamori's group investigated the role of GM3 in EGFR kinase inhibition, and showed that modification of the EGFR with $N$-linked glycan terminated with GlcNAc

Table 2. Molecular brightness of ErbB2-mYFP and Atto565-labeled ACP-erbB2

\begin{tabular}{lclc}
\hline & Soluble mYFP & ErbB2-short-mYFP & \\
$\begin{array}{c}\text { Molecular brightness } \\
\text { (mol/cluster) }\end{array}$ & $0.063 \pm 0.01$ & Inside macroclusters & $0.89 \pm 0.06(14.1)$ \\
& Soluble Atto565 & Outside macroclusters & $0.38 \pm 0.05(6.0)$ \\
& $0.19 \pm 0.01$ & SfP-ErbB2 & \\
$\begin{array}{c}\text { Molecular brightness } \\
\text { (mol/cluster) }\end{array}$ & Inside macroclusters & $0.81 \pm 0.04(7.8)$ \\
\hline
\end{tabular}

Cells expressing a 13-amino acid SfP-amino terminus (Garrett et al. 2002; Yin et al. 2006) tagged ErbB2 were labeled with Atto565-CoA using SfP transferase 2 days after transfection. Atto565-labeled and stably transfected ErbB2-mYFP-expressing cells were analyzed by the number and molecular brightness (N\&B) method. The molecular brightness of ErbB2 analyzed inside and outside macroclusters ( \pm s.E.M.) of $\sim 10$ cells are displayed as well as the brightness of the soluble monomeric fluorophores. To determine the average number of ErbB2 molecules in a molecular cluster (displayed in parentheses), cellular molecular brightness values were divided by that of the soluble fluorophore. 
promotes a direct interaction with GM3 (Yoon et al. 2006). In vitro studies with liposomes confirmed the exclusive interaction of ganglioside GM3 with the extracellular juxtamembrane domain of EGFR and a corresponding reduction of transphosphorylation, suggesting that this interaction causes an allosteric, inhibitory effect on autophosphorylation (Coskun et al. 2011). In contrast, ErbB2 is enriched in lipid rafts (Nagy et al. 2002) and is activated by its interaction with hyaluronic acid and CD44, both of which are up-regulated in several breast cancer lines (Ghatak et al. 2005). Interactions with the ECM and production of mucins may also lead to resistance to herceptin therapy (Friedländer et al. 2005; Nagy et al. 2005).

\section{WHAT IS THE STRUCTURE OF THE ErbB1 IN LIVING CELLS?}

The X-ray crystallographic structures of the extracellular and kinase domains of the ErbB family of receptors are discussed in detail in other articles. They have provided the basis for understanding (1) the requirement for dimerization for kinase activation, and (2) the mechanism of transphosphorylation (Shibuya 2013; Song et al. 2013; Barton et al. 2014; Hunter 2014). The first crystal structures of the liganded ErbB1 receptor (Garrett et al. 2002; Ogiso et al. 2002) revealed an extended extracellular structure with ligand binding between domains 1 and 3 and dimerization through domain 2, confirming an earlier model of Lemmon et al. (1997) of two EGF:two ErbB1 receptors. The subsequent ErbB2 structure of Garrett et al. (2003) also showed this extended structure. However, the unliganded, unactivated ErbB1 ectodomain crystallized in a self-inhibitory structure that oriented domain 1 in close proximity to the cell membrane (Ferguson et al. 2003). This structure has been presumed to be the form adopted by the inactive receptor in the plasma membrane. A number of in vivo studies on mutated ErbB1 receptors (Ozcan et al. 2006), antibody binding (Schmitz and Ferguson 2009), and cocrystal structures of antibody with ErbB1 (Li et al. 2005) have confirmed the existence of a configuration in which the EGF-binding face of domain 3 is exposed and ErbB1 is situated close to the cell membrane. Although ligandbinding transfers structural changes via the transmembrane domain in a manner causing reorganization of intracellular juxtamembrane and kinase domains into an active conformation (Yarden and Schlessinger 1987; Jura et al. 2009), it is unclear which extracellular configuration predominates in the presence of kinase inhibitors (e.g., quinazoline or PD168393) that stabilize the active state of the kinase domain (Stamos et al. 2002; Lu et al. 2012). A molecular dynamics (MD) simulation of EGFR in the presence of type I or type $11 / 2$ kinase inhibitors concludes that better efficacy in tumor therapy is achieved by stabilizing the inactive kinase conformation and specificity may be increased by understanding the flexibility of the various loops and helices in the presence of the inhibitors (Songtawee et al. 2013). Mutational studies of the juxtamembrane domain have confirmed its importance in activation (Red Brewer et al. 2009). Other MD simulations starting from the X-ray crystallographic structures of the extracellular domains or the kinase domains (Arkhipov et al. 2013) have addressed the influences of the membrane environment on conformation and thus, functional state. The importance of testing hypotheses generated from MD calculations with mutational studies or activity assays has been shown by Endres et al. (2013) and is certain to bear more fruit in the future.

There have been few studies of the structural features of the complete native ErbB1 receptor in the plasma membrane of intact living cells in the absence of ligand. Kozer et al. (2011) constructed an amino-terminally fused YFP EGFR chimera and measured FRET to a rhodamine labeled lipid probe in the plasma membrane. The investigators saw little or no change in the FRET efficiency after addition of EGF and concluded that the unliganded receptor is present in the plasma membrane primarily in the extended conformation. This transgene, however, shows spontaneous activation of the receptor even without addition of EGF, suggesting it may dimerize spontaneously via the YFP moiety and not adopt the normal configuration of the wildtype membrane-associated receptor. It is well 
D.J. Arndt-Jovin et al.

known that YFP lacking the A206K mutation has a strong tendency to dimerize (Zacharias et al. 2002). In addition, these investigators used $20 \mu \mathrm{m}$ phenyl arsine oxide (PAO) to inhibit endocytosis of the EGFR. PAO is a potent tyrosine phosphatase inhibitor (Garcia-Morales et al. 1990), and also specifically inhibits protein kinase IIa, which is responsible for maintaining the balance of PIP2 in the plasma membrane (Santos et al. 2013). PIP2 has been shown to influence the activity of the ErbB1 by binding to the intracellular juxtamembrane domain (Michailidis et al. 2011). The pleiotropic effects of this cellular effector, and the general effects of phosphatase inhibition, therefore, complicate the interpretation of these data.

We recently reported a biophysical determination of the orientation(s) of the ectodomain 1 of unliganded, nonactivated ErbB1 in living cells using FRET. The states before and after addition of EGF were assessed. An ErbB1-specific kinase inhibitor (PD153035) was used that prevents endocytosis but does not inhibit EGF binding (Ziomkiewicz et al. 2013). For these studies, we constructed a transgene ErbB1 with an acyl carrier protein sequence (Vivero-Pol et al. 2005; George 2006; Yin et al. 2006) between the signal peptide and the ErbB1 mature protein sequence. The mutated protein has unchanged functional properties, compared to wild-type ErbB1, and can be covalently labeled with a fluorophore at a specific serine in the acyl carrier tag. By measuring FRET between the acyl carrier tag and a novel lipid probe that localizes exclusively to the outer leaflet of the cell membrane (Kucherak et al. 2010), we determined the apparent relative distance to the membrane of the ACP tag under nonactivation and activation conditions. The fluorescence lifetime imaging microscopy (FLIM) experiments showed that the unliganded receptor is situated with its amino terminus significantly closer to the membrane than after EGF addition, thereby supporting the model in which most of the inactive receptor in the plasma membane of quiescent cells is in the self-inhibited, tethered configuration (Ziomkiewicz et al. 2013). Figure 2 shows representative FLIM images for the quiescent and activated conditions.

\section{SIGNALING FROM FILOPODIA}

RTKs expressed on nononcogenic cells under physiological conditions are required to sense directional gradients of growth factors for initiating rapid cellular division and directed migration in response to injury to the epithelium or for guidance during differentiation and development. Most experiments in the laboratory, however, involve isotropic exposure of tissue culture cells to growth factors in the working solution and monitoring the resulting cellular responses. The cells used are usually not polarized, and nor are they situated in a tissue context. It is known that very high levels of EGF can be antagonistic, causing cell death rather than activation or migration. Several years ago, we investigated the response of living cells to very low levels of EGF (5-50 pM) by tracking single receptors binding EGF coupled to QDs (Lidke et al. 2004, 2005). This technique allowed the observation of all stages of the receptor trafficking. The data also revealed a new paradigm according to which receptors situated far from the cell body on filopodia bind EGF, dimerize, and then attach to the actin filaments constituting the filapodial core. Actin treadmilling initiates retrograde transport of the anchored receptors toward the cell body, where they undergo endocytosis via clathrin-coated pits. The scheme depicting this mechanism is shown in Figure 3, and online Movie 1 shows the phenomenon (see online Movie 1 at http://cshperspectives.cshlp. org) for the online version. Our ongoing study of retrograde transport has revealed that Shcl is essential for the coupling of the activated ErbB1 to the actin filaments (MG Botelho et al., in prep.). Several of the other downstream effectors of the Erb1-associated signaling cascade are not membrane associated and interact with the receptor presenting on the surface of endocytic vesicles. We conclude that the cell may use receptors situated on the filopodia as sensors of growth factor gradients, serving to transduce the responses only if defined threshold levels are exceeded. That is, owing to the inherently nonlinear property of receptor activation, the filopodial mechanism of retrograde transport provides the cell with the capacity for selec- 


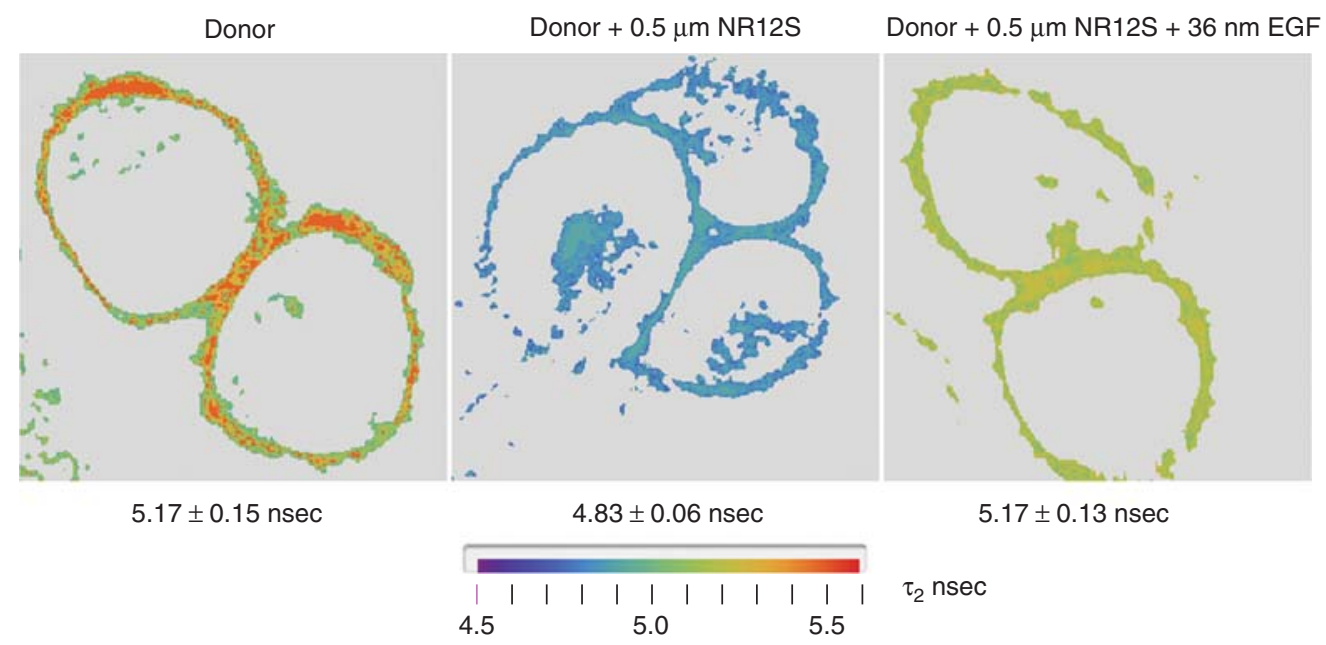

Figure 2. Conformational change of membrane-bound ErbB1 upon EGF binding as determined from FRET data. Stable Chinese hamster ovary $(\mathrm{CHO})$ cell line transfected with the acyl carrier protein tag fused to the amino terminus of the ErbB1 ectodomain. The target serine residue was covalently labeled by phosphopantetheine transferase with Atto390-CoA. Atto390 emits at $480 \mathrm{~nm}$ and served as the FRET donor. Living cells were examined in an Olympus-PicoQuant FLIM microscope system with two-photon, 80-MHz excitation at $740 \mathrm{~nm}$. Lifetime images for representative cells under three conditions are shown: (left) donor only; (middle) donor plus Nile Red12S (NR12S) membrane dye (applied at $0.5 \mu \mathrm{m}$ ) that localizes in the outer leaflet and acted as the FRET acceptor (Kucherak et al. 2010). NR12S absorbs broadly from 450 to 550 with a Förster $R_{0}$ of $5.4 \mathrm{~nm}$ and emits at $>590 \mathrm{~nm}$; and (right) donor and acceptor labeled cells bathed in $1 \mu \mathrm{m}$ ErbB1 kinase inhibitor PD153035 and exposed to $32 \mathrm{~nm}$ EGF (room temperature, $5 \mathrm{~min}$ ). Image acquisition was performed until the mean value for the brightest pixels reached 1000 counts using the PicoQuant SymphoTime TCSCP software. Pixel data (photon arrival times) were entered into a laboratory-generated Mathematica program for (i) selecting an analysis region of interest (ROI), (ii) filtering (masking and intensity ordering), and (iii) computing lifetimes from the intensity binned pixel data, assuming a two-component decay and using an analytical function to represent the experimental impulse response function (IRF) and the corresponding fluorescence time course (see Ziomkiewicz et al. 2013). The mean \pm s.e. lifetime values are given below each panel. There was an $\sim 7 \%$ drop in mean lifetime upon addition of the NR12S acceptor in the absence of EGF; this effect was substantially reversed upon addition of EGF (in the presence of kinase inhibitor) although the peak values originally observed in the absence of acceptor were not achieved. Data derived from experiments similar to those in Ziomkiewicz et al. (2013). We conclude that EGF binding, even in the absence of (auto)phosphorylation, leads to a conformational change, extending the ectodomain and thereby increasing the distance of the amino terminus from the plasma membrane in accordance with the model proposed from crystallographic analysis of isolated ErbB1 and its fragments. Larger separation correlates with a lower FLIM-detected FRET efficiency.

tively attenuating the response to low, physiologically nonrelevant levels of ligand, suppressing cellular migration and division under these conditions.

Epithelial cells have extensive filopodia and are covered with microvilli. These structures are enriched in growth factor and regulatory receptors and may regulate communication and signaling. Particularly long filopodia have been observed on the trophoectoderm in developing embryos which may promote communicating with the inner cell mass (Salas-Vidal and Lomeli 2004). Very short exposure to subsaturating levels of ligand results in predominance of activated receptor on microvilli and filopodia on A431 cells, as shown in Figure 4. Chung et al. (2010) calculated from single-particle analysis of $\mathrm{mAb}(\mathrm{Fab})$ binding that there was a predominance of receptors at the periphery of the cell. Surface plasmon resonance measurements based on gold immunolabeling reported by Wang et al. (2011) indicate that the density 
D.J. Arndt-Jovin et al.

of ErbB1 in A431 cells is higher on the filopodia than on the cell body.

\section{SIGNALING POTENTIATION AND \\ SIGNALING IN THE ABSENCE \\ OF NATIVE LIGAND}

The extent of protein-tyrosine phosphorylation in a cell reflects an equilibrium between the actions of protein-tyrosine kinases (PTKs) and protein-tyrosine phosphatases (PTPs), as has been shown in living cells by the Bastiaens group using FLIM to measure FRET between tagged phosphotyrosine antibodies and tagged ErbB proteins (Reynolds et al. 2003; Offterdinger et al. 2004; Grecco et al. 2010). Rhee and coworkers have studied the effects of cysteine oxidation on the inhibition of specific phosphotyrosine phosphatases as well as mitogen-activated protein kinase phosphatases (reviewed in Lee et al. 1998; Rhee et al. 2000; Janssen-Heininger et al. 2008) and the enhancement of RTK activity by localized hydrogen peroxide

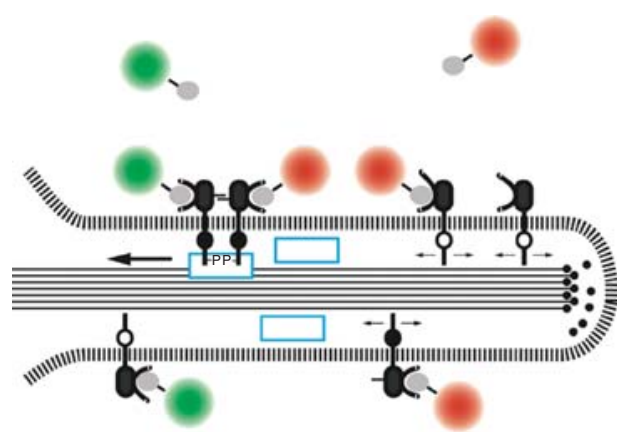

Figure 3. Filopodial retrograde transport of ErbB1. Recent studies identify Shcl as a component (blue box) linking the activated receptor to the actin filaments constituting the core of the filopodium (see text). (From Lidke et al. 2005; adapted, with permission, from Rockefeller University Press (C) 2005.)

production. The cell type and state-dependent regulation of the balanced PTK-PTP activity presumably accounts for apparent discrepancies in studies reporting the confinement or, alternatively, propagation of locally applied (microbead-mediated) activation of the ErbB1 (Ver-
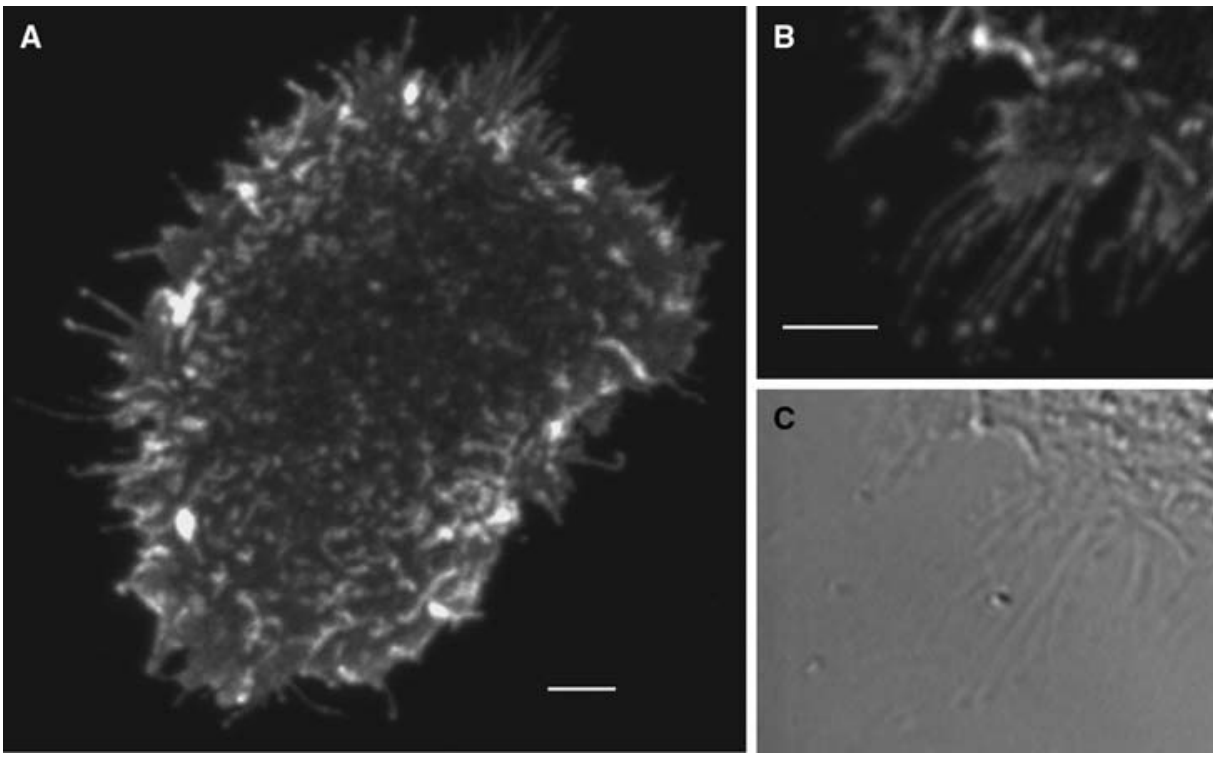

Figure 4. Preferential activation of ErbB1 on filopodia and microvilli with short exposure to EGF. Starved A431 cells were exposed for $40 \mathrm{sec}$ to $15 \mathrm{~nm}$ EGF and fixed directly in ice cold EtOH. Activated ErbB1 was detected by immunofluorescence using a phosphotyrosine-specific ErbB1 antibody ( pY1068) from cell signaling and a Cy3labeled secondary antibody. No signal was observed on cells not exposed to EGF. Images were taken on a Zeiss 510 Meta microscope using $532 \mathrm{~nm}$ excitation and emission $\geq 585 \mathrm{~nm}$. Background subtracted. Scale bars, $5 \mu \mathrm{m}$. 
Behavior of Intact ErbB RTKs in Live Cells

veer et al. 2000; Brock and Jovin 2003; Friedländer et al. 2005).

Other proteins may activate RTKs. Integrins have been implicated in ErbB signaling even without ligand binding (Yu et al. 2000; Bill et al. 2004), although Alexi et al. (2011) concluded that integrins were not involved but rather promote autocrine signaling. Recently, it was shown that neuregulin 1 binds both ErbB3 and integrin $\alpha 6 \beta 4$, forming a precipitable ternary complex that activates AKTand Erk1/2 (Ieguchi et al. 2010).

The fact that high densities of ErbB1 receptors increase the probability of unliganded dimer formation, as discussed in the first section, led us to investigate superparamagnetic $\mathrm{Fe}_{3} \mathrm{O}_{4}$ nanoparticles (SPIONS) as possible effectors of ErbB1 activation by a magnetic field
(Bharde et al. 2013). Such particles can be conjugated to mAbs or aptamers specific for an ErbB receptor and targeted directly to tumor cells. We have shown that anti-ErbB1-SPIONS (coupled with an antibody against ErbB1 that inhibits ligand binding) can selectively bind to ErbB1-expressing cells. Such complexes are inert but after application of a magnetic field the receptor is activated (Fig. 5) and subsequently internalized. These results suggest that activation of growth factor receptors may be triggered by ligand-independent molecular crowding resulting from overexpression and/or sequestration in membrane microdomains. Because nanoparticles can also be conjugated with drugs they constitute potential therapeutic agents. Somewhat larger nanoparticles also function well in magnetic resonance imaging (MRI).

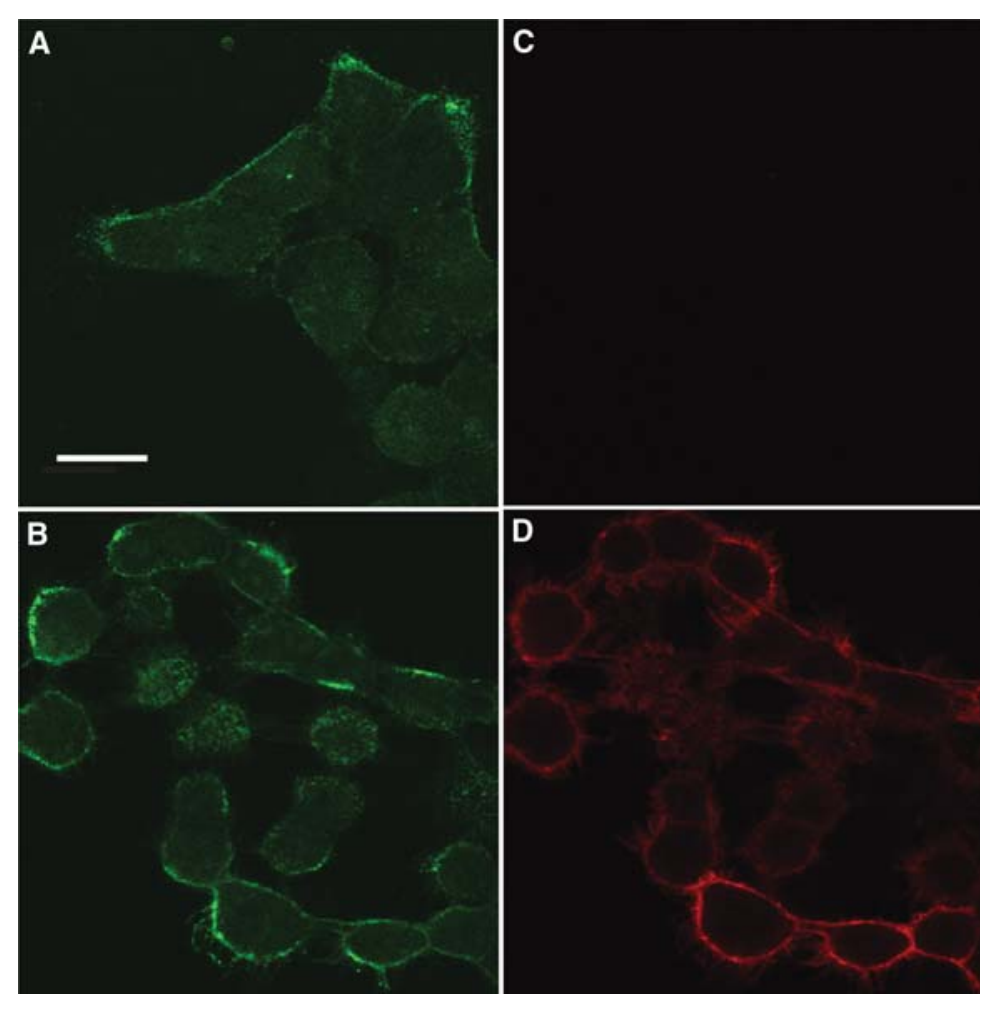

Figure 5. Binding of SPIONS to A431 cells and activation by exposure to a magnet for $180 \mathrm{sec}$. Panels $(A)$ and $(B)$ show specific binding of anti-ErbB1-targeted SPIONs on A431 cells after incubation for 15 min at $15^{\circ} \mathrm{C}$. Panels $(C)$ and $(D)$ show the amount of transphosphorylation of ErbB1 on the cells after no magnetic field $(C)$, or after application of a magnetic field for $180 \mathrm{sec}(D)$ by indirect immunofluorescence staining for anti-ErbB1 pY1068. Data from experiments are similar to those published in Bharde et al. (2013). Scale bar, $20 \mu \mathrm{m}$. 
D.J. Arndt-Jovin et al.

\section{CONCLUDING REMARKS}

We have reviewed the literature and unpublished data that bear on the disposition and structure of ErbB receptors in living cells. The understanding of the complex interactions and consequent downstream signaling of this key RTK family in the presence of various effectors is increasing, and effective models with testable biomedically relevant hypotheses are emerging. Importantly, there are new techniques available that allow interrogation of individual receptors in living cells, thereby providing new, quantitative estimations of the underlying equilibria and kinetic processes. Furthermore, our understanding of the disposition and activity of RTKs in tissue culture cell systems is assisting the design of more effective cancer therapeutic strategies for the $50 \%$ of all human tumors in which the ErbB family of RTKs is functionally up-regulated.

\section{ACKNOWLEDGMENTS}

We thank the numerous colleagues that have worked with us on ErbB-mediated signal transduction over many years for their lively discussions, interest, insight, and experimental expertise. Funding for the research in our laboratory is provided by the Max Planck Society, the EU FP6 STREP project FLUOROMAG (EC Contract No. 037465), and the Deutsche Forschungsgemeinschaft (DFG) Research Center for Molecular Physiology of the Brain (CMPB, Excellence Cluster EXC 171-FZT 103 "Microscopy at Nanometer Range").

\section{REFERENCES}

${ }^{*}$ Reference is also in this collection.

Alexi X, Berditchevski F, Odintsova E. 2011. The effect of cell-ECM adhesion on signalling via the ErbB family of growth factor receptors. Biochem Soc Trans 39: 568-573.

Arkhipov A, Shan Y, Das R, Endres NF, Eastwood MP, Wemmer DE, Kuriyan J, Shaw DE. 2013. Architecture and membrane interactions of the EGF receptor. Cell 152: $557-569$.

* Barton WA, Dalton AC, Seegar TCM, Himanen JP, Nikolov DB. 2014. Tie2 and Eph receptor tyrosine kinase activation and signaling. Cold Spring Harb Perspect Biol doi: 10.1101/cshperspect.a009142.
Berger MB, Mendrola JM, Lemmon MA. 2004. ErbB3/ HER3 does not homodimerize upon neuregulin binding at the cell surface. FEBS Lett 569: 332-336.

Bharde AA, Palankar R, Fritsch C, Klaver A, Kanger JS, Jovin TM, Arndt-Jovin DJ. 2013. Magnetic nanoparticles as mediators of ligand-free activation of EGFR signaling. Plos ONE 8: e68879.

Bill HM, Knudsen B, Moores SL, Muthuswamy SK, Rao VR, Brugge JS, Miranti CK. 2004. Epidermal growth factor receptor-dependent regulation of integrin-mediated signaling and cell cycle entry in epithelial cells. Mol Cell Biol 24: 8586-8599.

Brock R, Jovin TM. 2003. Quantitative image analysis of cellular protein translocation induced by magnetic microspheres: Application to the EGF receptor. Cytometry 52A: $1-11$.

Brock R, Hamelers IHL, Jovin TM. 1999. Comparison of fixation protocols for adherent cultured cells applied to a GFP fusion protein of the epidermal growth factor receptor. Cytometry 35: 353-362.

Cho I, Cho HS, Mason K, Ramyar KX, Stanley AM, Gabelli SB, Denney DW Jr, Leahy DJ. 2003. Structure of the extracellular region of HER2 alone and in complex with the Herceptin Fab. Nature 421: 756-760.

Chung I, Akita R, Vandlen R, Toomre D, Schlessinger J, Mellman I. 2010. Spatial control of EGF receptor activation by reversible dimerization on living cells. Nature 464: $783-787$.

Citri A, Skaria KB, Yarden Y. 2003. The deaf and the dumb: The biology of ErbB-2 and ErbB-3. Exp Cell Res 284: 5465.

Coskun U, Grzybek M, Drechsel D, Simons K. 2011. Regulation of human EGF receptor by lipids. Proc Natl Acad Sci 108: 9044-9048.

Digman MA, Dalal R, Horwitz AF, Gratton E. 2008. Mapping the number of molecules and brightness in the laser scanning microscope. Biophys J 94: 2320-2332.

Endres NF, Das R, Smith AW, Arkhipov A, Kovacs E, Huang Y, Pelton JG, Shan Y, Shaw DE, Wemmer DE, et al. 2013. Conformational coupling across the plasma membrane in activation of the EGF receptor. Cell 152: 543-556.

Ferguson KM, Berger MB, Mendrola JM, Cho HS, Leahy DJ, Lemmon MA. 2003. EGF activates its receptor by removing interactions that autoinhibit ectodomain dimerization. Mol Cell 11: 507-517.

Friedländer E, Nagy P, Arndt-Jovin DJ, Jovin TM, Szöllösi J, Vereb G. 2005. Signal transduction of erbB receptors in trastuzumab (Herceptin) sensitive and resistant cell lines: Local stimulation using magnetic microspheres as assessed by quantitative digital microscopy. Cytometry 67A: $161-171$.

Gadella TWJ Jr, Jovin TM. 1995. Oligomerization of epidermal growth factor receptors on A431 cells studied by time-resolved fluorescence imaging microscopy: A stereochemical model for tyrosine kinase receptor activation. J Cell Biol 129: 1543-1558.

Garcia-Morales P, Minami Y, Luong E, Klausner RD, Samelson LE. 1990. Tyrosine phosphorylation in T cells is regulated by phosphatase activity: Studies with phenylarsine oxide. Proc Natl Acad Sci 87: 9255-9259. 
Garrett TPJ, McKern NM, Lou MZ, Elleman TC, Adams TE, Lovrecz GO, Zhu HJ, Walker F, Frenkel MJ, Hoyne PA, et al. 2002. Crystal structure of a truncated epidermal growth factor receptor extracellular domain bound to transforming growth factor $\alpha$. Cell 110: 763-773.

Garrett TPJ, McKern NM, Lou MZ, Elleman TC, Adams TE, Lovrecz GO, Kofler M, Jorissen RN, Nice EC, Burgess AW, et al. 2003. The crystal structure of a truncated ErbB2 ectodomain reveals an active conformation, poised to interact with other ErbB receptors. Mol Cell 11:495-505.

George N. 2006. A new method for protein labeling with small molecules based on acyl carrier protein. Chemistry and chemical genetics, 149 pp. PhD thesis, École Polytechnique Fédérale de Lausanne, Lausanne.

Ghatak S, Misra S, Toole BP. 2005. Hyaluronan constitutively regulates ErbB2 phosphorylation and signaling complex formation in carcinoma cells. J Biol Chem 280: 8875-8883.

Gilmour LMR, Macleod KG, McCaig A, Sewell JM, Gullick WJ, Smyth JF, Langdon SP. 2002. Neuregulin expression, function, and signaling in human ovarian cancer cells. Clin Cancer Res 8: 3933-3942.

Grecco HE, Roda-Navarro P, Girod A, Hou J, Frahm T, Truxius DC, Pepperkok R, Squire A, Bastiaens PI. 2010. In situ analysis of tyrosine phosphorylation networks by FLIM on cell arrays. Nat Methods 2010: 9.

Holbro T, Beerli RR, Maurer F, Koziczak M, Barbas CF, Hynes NE. 2003. The ErbB2/ErbB3 heterodimer functions as an oncogenic unit: ErbB2 requires ErbB3 to drive breast tumor cell proliferation. Proc Natl Acad Sci 100: 8933-8938.

* Hunter T. 2014. The genesis of tyrosine phosphorylation. Cold Spring Harb Perspect Biol doi: 10.1101/cshperspect.a020644.

Ieguchi K, Fujita M, Ma Z, Davari P, Taniguchi Y, Sekiguchi K, Wang BZ, Takada YK, Takada Y. 2010. Direct binding of the EGF-like domain of neuregulin-1 to integrins $(\alpha v \beta 3$ and $\alpha 6 \beta 4)$ is involved in neuregulin-1/ErbB signaling. J Biol Chem 285: 31388-31398.

Janssen-Heininger YM, Mossman BT, Heintz NH, Forman HJ, Kalyanaraman B, Finkel T, Stamler JS, Rhee SG, van der Vliet A. 2008. Redox-based regulation of signal transduction: Principles, pitfalls, and promises. Free Radic Biol Med 45: 1-17.

Jura N, Endres NF, Engel K, Deindl S, Das R, Lamers MH, Wemmer DE, Zhang X, Kuriyan J. 2009. Mechanism for activation of the EGF receptor catalytic domain by the juxtamembrane segment. Cell 137: 1293-1307.

Kozer N, Henderson C, Jackson JT, Nice EC, Burgess AW, Clayton AH. 2011. Evidence for extended YFP-EGFR dimers in the absence of ligand on the surface of living cells. Phys Biol 8: 066002.

Kucherak OA, Oncul S, Darwich Z, Yushchenko DA, Arntz Y, Didier P, Mely Y, Klymchenko AS. 2010. Switchable nile red-based probe for cholesterol and lipid order at the outer leaflet of biomembranes. J Am Chem Soc 132: 4907-4916.

Kusumi A, Suzuki KG, Kasai RS, Ritchie K, Fujiwara TK. 2011. Hierarchical mesoscale domain organization of the plasma membrane. Trends Biochem Sci 36: 604-615.

Lee S-R, Kwon K-S, Kim S-R, Rhee SG. 1998. Reversible inactivation of protein-tyrosine phosphatase $1 \mathrm{~B}$ in
A431 cells stimulated with epidermal growth factor. $J$ Biol Chem 273: 15366-15372.

Lemmon MA, Bu ZM, Ladbury JE, Zhou M, Pinchasi D, Lax I, Engelman DM, Schlessinger J. 1997. Two EGF molecules contribute additively to stabilization of the EGFR dimer. EMBO J 16: 281-294.

Li S, Schmitz KR, Jeffrey PD, Wiltzius JJ, Kussie P, Ferguson KM. 2005. Structural basis for inhibition of the epidermal growth factor receptor by cetuximab. Cancer Cell 7: 301-311.

Lidke DS, Nagy P, Heintzmann R, Arndt-Jovin DJ, Post JN, Grecco H, Jares-Erijman EA, Jovin TM. 2004. Quantum dot ligands provide new insights into erbB/HER receptor-mediated signal transduction. Nat Biotechnol 22: 198-203.

Lidke DS, Lidke KA, Rieger B, Jovin TM, Arndt-Jovin DJ. 2005. Reaching out for signals: Filopodia sense EGF and respond by directed retrograde transport of activated receptors. J Cell Biol 170: 619-626.

Low-Nam ST, Lidke KA, Cutler PJ, Roovers RC, van Bergen en Henegouwen PMP, Wilson BS, Lidke DS. 2011. ErbB1 dimerization is promoted by domain co-confinement and stabilized by ligand binding. Nat Struct Mol Biol 18: $1244-1249$.

Lu C, Mi LZ, Schurpf T, Walz T, Springer TA. 2012. Mechanisms for kinase-mediated dimerization of the epidermal growth factor receptor. J Biol Chem 287: $38244-$ 38253.

Martin-Fernandez M, Clarke DT, Tobin MJ, Jones SV, Jones GR. 2002. Preformed oligomeric epidermal growth factor receptors undergo an ectodomain structure change during signaling. Biophys J 82: 2415-2427.

Michailidis IE, Rusinova R, Georgakopoulos A, Chen Y, Iyengar R, Robakis NK, Logothetis DE, Baki L. 2011. Phosphatidylinositol-4,5-bisphosphate regulates epidermal growth factor receptor activation. Pflugers Arch 461: 387-397.

Moriki T, Maruyama H, Maruyama IN. 2001. Activation of preformed EGF receptor dimers by ligand-induced rotation of the transmembrane domain. J Mol Biol 311: 1011-1026.

Nagy P, Bene L, Balazs M, Hyun WC, Lockett SJ, Chiang NY, Waldman F, Feuerstein BG, Damjanovich S, Szollosi J. 1998. EGF-induced redistribution of erbB2 on breast tumor cells: Flow and image cytometric energy transfer measurements. Cytometry 32: 120-131.

Nagy P, Jenei A, Kirsch AK, Szollosi J, Damjanovich S, Jovin TM. 1999. Activation-dependent clustering of the erbB2 receptor tyrosine kinase detected by scanning near-field optical microscopy. J Cell Sci 112: 1733-1741.

Nagy P, Vereb G, Sebestyen Z, Horvath G, Lockett SJ, Damjanovich S, Park JW, Jovin TM, Szollosi J. 2002. Lipid rafts and the local density of ErbB proteins influence the biological role of homo- and heteroassociations of ErbB2. Cell Sci 115: 4251-4262.

Nagy P, Friedländer E, Tanner M, Kapanen AI, Carraway KL, Isola J, Jovin TM. 2005. Decreased accessibility and lack of activation of erbB2 in JIMT-1, a Herceptin-resistant, MUC-4-expressing breast cancer cell line. Cancer Res 65: 473-482.

Nagy P, Claus J, Jovin TM, Arndt-Jovin DJ. 2010. Distribution of resting and ligand-bound ErbB1 and ErbB2 re- 
D.J. Arndt-Jovin et al.

ceptor tyrosine kinases in living cells using number and brightness analysis. Proc Natl Acad Sci 107: 1652416529.

Offterdinger M, Bastiaens PI. 2008. Prolonged EGFR signaling by ERBB2-mediated sequestration at the plasma membrane. Traffic 9: 147-155.

Offterdinger M, Georget V, Girod A, Bastiaens PI. 2004 Imaging phosphorylation dynamics of the epiderma growth factor receptor. J Biol Chem 279: 36972-36981.

Ogiso H, Ishitani R, Nureki O, Fukai S, Yamanaka M, Kim JH, Saito K, Sakamoto A, Inoue M, Shirouzu M, et al. 2002. Crystal structure of the complex of human epidermal growth factor and receptor extracellular domains. Cell 110: 775-787.

Ozcan F, Klein P, Lemmon MA, Lax I, Schlessinger J. 2006. On the nature of low- and high-affinity EGF receptors on living cells. 103: 5735-5740.

Park E, Baron R, Landgraf R. 2008. Higher-order association states of cellular ERBB3 probed with photo-cross-linkable aptamers. Biochemistry 47: 11992-12005.

Red Brewer M, Choi SH, Alvarado D, Moravcevic K, Pozzi A, Lemmon MA, Carpenter G. 2009. The juxtamembrane region of the EGF receptor functions as an activation domain. Mol Cell 34: 641-651.

Reynolds AR, Tischer C, Verveer PJ, Rocks O, Bastiaens PI. 2003. EGFR activation coupled to inhibition of tyrosine phosphatases causes lateral signal propagation. Nat Cell Biol 5: 447-453.

Rhee SG, Bae YS, Lee SR, Kwon J. 2000. Hydrogen peroxide: A key messenger that modulates protein phosphorylation through cysteine oxidation. Sci STKE 2000: el.

Rubin I, Yarden Y. 2001. The basic biology of HER2. Ann Oncol 12: 3-8.

Saffarian S, Li Y, Elson EL, Pike LJ. 2007. Oligomerization of the EGF receptor investigated by live cell fluorescence intensity distribution analysis. Biophys J 93: 1021-1031.

Sako Y, Minoghchi S, Yanagida T. 2000. Single-molecule imaging of EGFR signalling on the surface of living cells. Nat Cell Biol 2: 168-172.

Salas-Vidal E, Lomeli H. 2004. Imaging filopodia dynamics in the mouse blastocyst. Dev Biol 265: 75-89.

Santos Mde S, Naal RM, Baird B, Holowka D. 2013. Inhibitors of PI(4,5)P2 synthesis reveal dynamic regulation of IgE receptor signaling by phosphoinositides in RBL mast cells. Mol Pharmacol 83: 793-804.

Schmitz KR, Ferguson KM. 2009. Interaction of antibodies with ErbB receptor extracellular regions. Exp Cell Res 315: 659-670.

* Shibuya M. 2013. VEGFR and type-V RTK activation and signaling. Cold Spring Harb Perspect Biol doi: 10.1101/ cshperspect.a009092.

Smirnova T, Zhou ZN, Flinn RJ, Wyckoff J, Boimel PJ, Pozzuto M, Coniglio SJ, Backer JM, Bresnick AR, Condeelis JS, et al. 2011. Phosphoinositide 3-kinase signaling is critical for ErbB3-driven breast cancer cell motility and metastasis. Oncogene 4: 275.

* Song S, Rosen KM, Corfas G. 2013. Biological function of nuclear receptor tyrosine kinase action. Cold Spring Harb Perspect Biol 5: a009001.

Songtawee N, Gleeson MP, Choowongkomon K. 2013. Computational study of EGFR inhibition: Molecular dy- namics studies on the active and inactive protein conformations. J Mol Model 19: 497-509.

Stamos J, Sliwkowski MX, Eigenbrot C. 2002. Structure of the epidermal growth factor receptor kinase domain alone and in complex with a 4-anilinoquinazoline inhibitor. J Biol Chem 277: 46265-46272.

Szabó A, Horváth G, Szöllősi J, Nagy P. 2008. Quantitative characterization of the large-scale association of ErbB1 and ErbB2 by flow cytometric homo-FRET measurements. Biophys J 95: 2086-2096.

Tanaka KA, Suzuki KG, Shirai YM, Shibutani ST, Miyahara MS, Tsuboi H, Yahara M, Yoshimura A, Mayor S, Fujiwara TK, et al. 2010. Membrane molecules mobile even after chemical fixation. Nat Methods 7: 865-866.

Tynan CJ, Clarke DT, Coles BC, Rolfe DJ, Martin-Fernandez ML, Webb SE. 2012. Multicolour single molecule imaging in cells with near infra-red dyes. PLoS ONE 7: e36265.

Tyson DR, Larkin S, Hamai Y, Bradshaw RA. 2003. PC12 cell activation by epidermal growth factor receptor: Role of autophosphorylation sites. Int J Dev Neurosci 21: $63-74$.

Verveer PJ, Wouters FS, Reynolds AR, Bastiaens PI. 2000. Quantitative imaging of lateral ErbB1 receptor signal propagation in the plasma membrane. Science 290: 1567-1570.

Vivero-Pol L, George N, Krumm H, Johnsson K, Johnsson N. 2005. Multicolor imaging of cell surface proteins. J Am Chem Soc 127: 12770-12771.

* Volinsky N, Kholodenko BN. 2013. Complexity of receptor tyrosine kinase signaling processing. Cold Spring Harb Perspect Biol 5: a009043.

Wang Z, Zhang L, Yeung TK, Chen X. 1999. Endocytosis deficiency of epidermal growth factor (EGF) receptorErbB2 heterodimers in response to EGF stimulation. Mol Biol Cell 10: 1621-1636.

Wang J, Boriskina SV, Wang H, Reinhard BM. 2011. Illuminating epidermal growth factor receptor densities on filopodia through plasmon coupling. ACS Nano 5: 66196628.

Yang S, Raymond-Stintz MA, Ying W, Zhang J, Lidke DS, Steinberg SL, Williams L, Oliver JM, Wilson BS. 2007. Mapping ErbB receptors on breast cancer cell membranes during signal transduction. J Cell Sci 120: 2763-2773.

Yarden Y, Schlessinger J. 1987. Self-phosphorylation of epidermal growth factor receptor: Evidence for a model of intermolecular allosteric activation. Biochemistry 26: 1434-1442.

Yin J, Lin A, Golan D, Walsh C. 2006. Site-specific protein labeling by Sfp phosphopantetheinyl transferase. Nat Protoc 1: 280-285.

Yoon SJ, Nakayama K, Hikita T, Handa K, Hakomori SI. 2006. Epidermal growth factor receptor tyrosine kinase is modulated by GM3 interaction with $N$-linked GlcNAc termini of the receptor. Proc Natl Acad Sci 103: 1898718991.

Yu X, Miyamoto S, Mekada E. 2000. Integrin $\alpha 2 \beta 1$-dependent EGF receptor activation at cell-cell contact sites. J Cell Sci 113: 2139-2147.

Zacharias DA, Violin JD, Newton AC, Tsien RY. 2002. Partitioning of lipid-modified monomeric GFPs into 
Behavior of Intact ErbB RTKs in Live Cells

membrane microdomains of live cells. Science 296: 913916.

Zhang Y, Opresko L, Shankaran H, Chrisler WB, Wiley HS, Resat H. 2009. HER/ErbB receptor interactions and signaling patterns in human mammary epithelial cells. $B M C$ Cell Biol 10: 78.
Ziomkiewicz I, Loman A, Klement R, Fritsch C, Klymchenko A, Bunt G, Jovin TM, Arndt-Jovin DJ. 2013. Dynamic conformational transitions of the EGF receptor in living mammalian cells determined by FRET and fluorescence lifetime imaging microscopy. Cytometry A 83A: 794-805. 


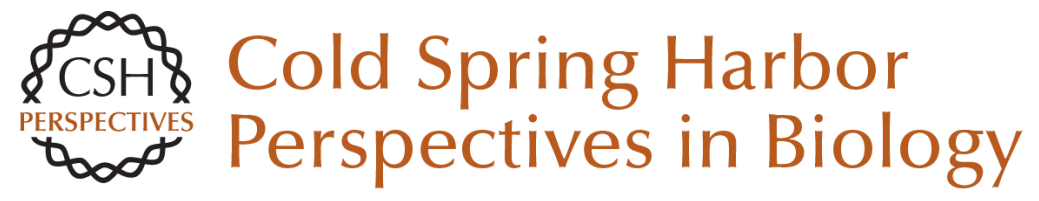

\section{Structure-Function Relationships of ErbB RTKs in the Plasma Membrane of Living Cells}

Donna J. Arndt-Jovin, Michelle G. Botelho and Thomas M. Jovin

Cold Spring Harb Perspect Biol 2014; doi: 10.1101/cshperspect.a008961

Subject Collection Signaling by Receptor Tyrosine Kinases

CSF-1 Receptor Signaling in Myeloid Cells

E. Richard Stanley and Violeta Chitu

The EGFR Family: Not So Prototypical Receptor

Tyrosine Kinases

Mark A. Lemmon, Joseph Schlessinger and

Kathryn M. Ferguson

Tie2 and Eph Receptor Tyrosine Kinase Activation and Signaling

William A. Barton, Annamarie C. Dalton, Tom C.M. Seegar, et al.

The Spatiotemporal Organization of ErbB Receptors: Insights from Microscopy

Christopher C. Valley, Keith A. Lidke and Diane S. Lidke

Insulin Receptor Signaling in Normal and Insulin-Resistant States

Jérémie Boucher, André Kleinridders and C. Ronald Kahn

Central Role of RET in Thyroid Cancer Massimo Santoro and Francesca Carlomagno

Receptor Tyrosine Kinase-Mediated Angiogenesis Michael Jeltsch, Veli-Matti Leppänen, Pipsa Saharinen, et al.
The Genesis of Tyrosine Phosphorylation Tony Hunter

Structure-Function Relationships of ErbB RTKs in the Plasma Membrane of Living Cells Donna J. Arndt-Jovin, Michelle G. Botelho and Thomas M. Jovin

Receptor Tyrosine Kinases: Legacy of the First Two Decades Joseph Schlessinger

The Role of Ryk and Ror Receptor Tyrosine Kinases in Wnt Signal Transduction Jennifer Green, Roel Nusse and Renée van Amerongen

Regulation of Receptor Tyrosine Kinase Ligand Processing Colin Adrain and Matthew Freeman

Molecular Mechanisms of SH2- and PTB-Domain-Containing Proteins in Receptor Tyrosine Kinase Signaling Melany J. Wagner, Melissa M. Stacey, Bernard A. Liu, et al.

Eph Receptor Signaling and Ephrins Erika M. Lisabeth, Giulia Falivelli and Elena B. Pasquale

For additional articles in this collection, see http://cshperspectives.cshlp.org/cgi/collection/

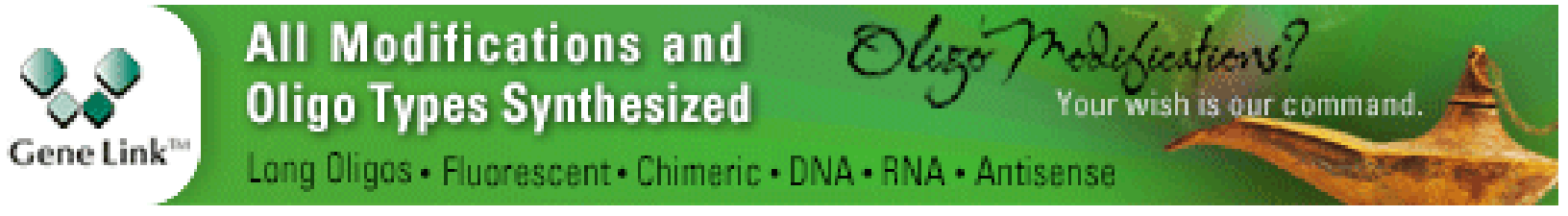




\section{Biology of the TAM Receptors \\ Greg Lemke}

Effects of Membrane Trafficking on Signaling by

Receptor Tyrosine Kinases

Marta Miaczynska

For additional articles in this collection, see http://cshperspectives.cshlp.org/cgi/collection/

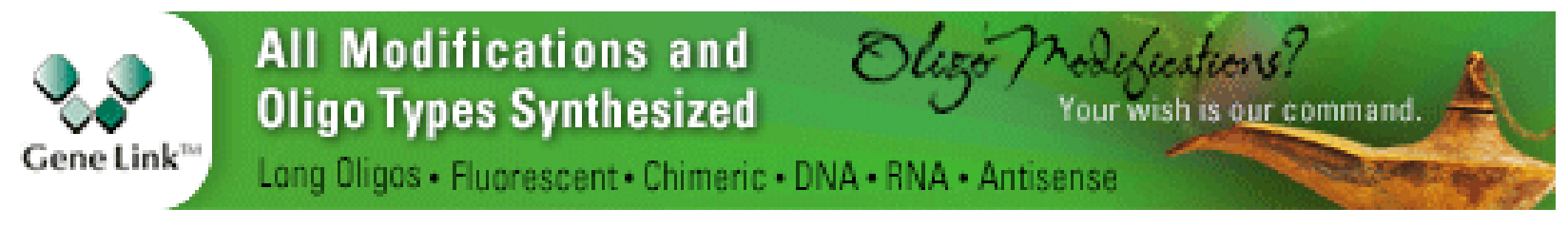

Copyright @ 2014 Cold Spring Harbor Laboratory Press; all rights reserved 